\title{
INTRODUÇÃO DE ASPECTOS DE NATUREZA DA CIÊNCIA NO PLANEJAMENTO DE SITUAÇÕES DIFERENCIADAS DE ENSINO DE CIÊNCIAS
}

\author{
Introduction of Nature of Science Aspects' in Planning Differentiated Science Teaching \\ Situations
}

\author{
Ellen Catharina Ponciano Siqueira ${ }^{1}$ \\ Monique Santos ${ }^{2}$ \\ Roberta Guimarães Corrêa ${ }^{3}$
}

\begin{abstract}
Resumo: Visando auxiliar o planejamento de situações de ensino que possam contribuir para a ampliação da visão sobre Ciências de estudantes da Educação Básica e, consequentemente, favorecer o processo de desenvolvimento de alfabetização científica, este artigo discute a inserção contextualizada e explícita de aspectos de Natureza da Ciência (NdC) norteada por um referencial teórico-metodológico que aborda tal temática. Foi elaborada uma sequência didática composta por três atividades: a primeira com o objetivo de identificar as ideias iniciais de estudantes sobre Ciências; a segunda com o objetivo de introduzir aspectos de NdC de maneira contextualizada e explícita; e a terceira com o objetivo de identificar a ocorrência e extensão de uma ampliação das visões iniciais. O referencial teórico-metodológico também guiou a elaboração de orientações para o professor desenvolver tais atividades de modo a identificar e inserir aspectos de $\mathrm{NdC}$ durante as discussões em sala de aula. Tanto o processo de elaboração da sequência didática como ela própria evidenciam como o referencial teóricometodológico pode ser utilizado para estruturar atividades de ensino que visem introduzir diversos aspectos de $\mathrm{NdC}$ de maneira contextualizada e explícita no ensino de Ciências. Ademais, o referencial também contribuiu para a ampliação das visões sobre Ciências das próprias autoras deste trabalho.
\end{abstract}

Palavras-chave: Natureza da Ciência. Ensino de Ciências. Ferramenta Teórico-metodológica.

\begin{abstract}
In order to help planning teaching situations that can contribute to enhance secondary students' views about science and, consequently, to support the process of acquisition of scientific literacy, this paper discusses how a theoretical-methodological framework that addresses aspects of Nature of Science (NOS) guided their contextual and explicit insertion. A didactic sequence composed of three activities was produced. Their aims are to probe students' initial ideas about science, to introduce aspects of NOS in a contextualized and explicit manner, and to identify the possible occurrence and extension of
\end{abstract}

\footnotetext{
${ }^{1}$ Graduada em Química Licenciatura pela Universidade Federal de Minas Gerais. Orcid: https://orcid.org/00000002-2059-8658. E-mail: ellenponciano@gmail.com

${ }^{2}$ Graduada em Química Licenciatura, Mestre e Doutoranda em Educação e Ciências, todos pela Universidade Federal de Minas Gerais. Orcid: https://orcid.org/0000-0001-6042-0312. E-mail: moniquersqui@gmail.com

${ }^{3}$ Graduada em Química Licenciatura, Mestre em Química e Doutora em Ciências, todos pela Universidade Federal de São Carlos. Professora Adjunta do Departamento de Química do Instituto de Ciências Exatas da Universidade Federal de Minas Gerais. Orcid: https://orcid.org/0000-0003-4720-5401. E-mail: robertacorrea@ufmg.br
} 
an expansion of the students' view, respectively. Besides guiding the production of the activities, the theoretical-methodological framework also supported the generation of guidelines for supporting teachers' actions when conducting the activities aiming at introducing aspects of NOS. Both the process of producing the didactic sequence and the sequence itself show how the theoretical-methodological framework can be used to base teaching activities that aim to introduce aspects of NOS in science teaching in a contextualized and explicit way. In addition, the framework also contributed to enhance our own view about science.

Keywords: Nature of Science. Science Education. Theoretical-methodological Tool.

\title{
1 Introdução
}

Nas últimas décadas, alguns pesquisadores (MILLAR; OSBORNE, 1998; OSBORNE et al., 2003) têm destacado a importância de um ensino que possa contribuir para a ampliação da visão sobre Ciências ${ }^{4}$ de estudantes, que favoreça a compreensão e reflexão sobre os processos de construção do conhecimento científico. $\mathrm{O}$ ensino nessa perspectiva tem como objetivo promover e alcançar uma alfabetização científica mais ampla, isto é, contribuir para a formação de cidadãos crítico-reflexivos (SASSERON; CARVALHO, 2011). Sob essa perspectiva, vários pesquisadores (ALLCHIN, 2011; IRZIK; NOLA, 2011; MATHEWS, 2012; JUSTI; ERDURAN, 2015; SANTOS; MAIA; JUSTI, 2020) têm pesquisado sobre a importância de introduzir aspectos de Natureza da Ciência $(\mathrm{NdC})$ no ensino de Ciências.

Na literatura da área de Educação em Ciências, existem várias definições para o termo NdC. Porém, nós adotamos a apresentada por McComas (2008) devido à sua coerência com o referencial teórico-metodológico adotado neste trabalho. De acordo com o autor, NdC é:

\begin{abstract}
[...] um domínio híbrido que combina aspectos de vários estudos sociais da Ciência, incluindo História, Filosofia e Sociologia da Ciência, combinados com a pesquisa das Ciências da Cognição, como a Psicologia, em uma rica descrição da Ciência; como ela funciona, a forma de operar dos cientistas, enquanto um grupo social; e como a própria sociedade tanto dirige como reage aos empreendimentos científicos (MCCOMAS, 2008, p. 249, tradução nossa).
\end{abstract}

Sob essa ótica, os pesquisadores, mencionados anteriormente, têm ressaltado a importância de aspectos de NdC serem introduzidos de maneira contextualizada (a partir de um contexto que viabiliza tal introdução) e/ou explícita (a partir de discussões abertas e claras). Isto porque, ao introduzir aspectos de $\mathrm{NdC}$ dessa(s) maneira(s) no ensino, pode-se favorecer a ampliação da visão sobre Ciências de estudantes.

Todavia, apesar da importância de introduzir aspectos de $\mathrm{NdC}$ de tal(is) maneira(s) no ensino, e da existência de alguns referenciais teóricos como: (i) a lista de princípios (LEDERMAN; ABD-EL-KHALICK; BELL; SCHWARTZ, 2002); (ii) o perfil de dimensões de confiabilidade da ciência (ALLCHIN, 2011; 2013; 2017); e (iii) a abordagem baseada na semelhança de família (IRZIK; NOLA, 2011; 2014), professores de Ciências ainda apresentam dificuldades em inserir aspectos de $\mathrm{NdC}$ em contextos de ensino. Talvez o fato de tais referenciais serem apenas teóricos possa explicar a dificuldade que professores têm de, por exemplo, estruturar atividades de ensino com tal propósito. Pensando nisso, Erduran e Dagher (2014) ampliaram a abordagem baseada na semelhança de família com o objetivo de tornar tal referencial também metodológico; e Justi e Erduran (2015) propuseram o Modelo de Ciências para o Ensino de Ciências (MoCEC), com o objetivo específico de que ele pudesse

\footnotetext{
${ }^{4} \mathrm{O}$ termo sobre Ciências, neste artigo, é utilizado como sinônimo do termo Natureza da Ciência (NdC).
} 
ser usado por professores como suporte no planejamento de atividades dessa natureza. Entretanto, não encontramos trabalhos baseados nos últimos dois referenciais teóricometodológicos que elucidassem como esses foram utilizados para tal finalidade.

Considerando essa lacuna, neste artigo discutimos o planejamento de uma sequência didática a partir de um referencial teórico-metodológico elaborado para subsidiar professores na introdução, de maneira contextualizada e explícita, de aspectos de NdC no ensino de Ciências.

\section{Referencial teórico-metodológico}

Neste trabalho, utilizamos como referencial teórico-metodológico a segunda versão do Modelo de Ciências para o Ensino de Ciências (MoCEC v.2) (SANTOS; MAIA; JUSTI, 2020). Tal opção se baseou no fato de ele ter sido elaborado para subsidiar o trabalho de professores e de favorecer uma caracterização ampla e complexa da Ciência. Assim como a versão original, o MoCEC v.2 se baseia em duas premissas: (i) a Ciência é uma complexa atividade cognitiva, epistêmica e social, que pode e tem sido caracterizada a partir de diferentes áreas de conhecimento; e (ii) os argumentos sobre Ciências devem se basear em evidências oriundas de diferentes áreas de conhecimento para que o ensino favoreça a ampliação da visão sobre Ciências de indivíduos envolvidos no processo de ensino e aprendizagem (JUSTI; ERDURAN, 2015).

O MoCEC v. 2 caracteriza a Ciência de maneira ampla e complexa ao considerar que essa deve ser vista a partir de várias áreas de conhecimento, tanto de forma isolada como em conjunto. Tais áreas abrangem: (i) Filosofia da Ciência, que se relaciona ao processo de construção do conhecimento científico; (ii) Psicologia da Ciência, que abarca as relações intrapessoais de um indivíduo com os processos de produção e uso do conhecimento científico; (iii) Antropologia da Ciência, que se relaciona aos processos de produção e desenvolvimento do conhecimento científico; (iv) Sociologia da Ciência, que evidencia que a Ciência é uma prática social; (v) Economia da Ciência, que estuda os impactos sofridos e/ou exercidos pela mercantilização e comercialização do conhecimento científico em suas etapas de produção e aplicação; e (vi) História da Ciência, que estuda o desenvolvimento dos conhecimentos científicos ao longo do tempo. O modelo também considera que novas áreas de conhecimento podem emergir, ser abordadas futuramente ou se fundir (SANTOS; MAIA; JUSTI, 2020). Além disso, a Ciência pode ser vista sob a perspectiva de diversos aspectos de NdC presentes em cada uma dessas áreas. Contudo, neste artigo, apresentamos (na seção Resultados e discussões) apenas a caracterização de alguns dos aspectos de $\mathrm{NdC}$ contemplados em cada uma das atividades constituintes da sequência didática a título de exemplificação.

Para que o leitor tenha uma ideia geral desses aspectos, esses são apresentados no Quadro 1. Este quadro apresenta 37 aspectos de $\mathrm{NdC}$ no total, sendo: (i) três da área de Filosofia da Ciência; (ii) treze da área de Psicologia da Ciência; (iii) dois da área de Antropologia da Ciência; (iv) seis da área de Sociologia da Ciência; (v) oito da área de Economia da Ciência; e (vi) cinco da área de História da Ciência. Ressaltamos que alguns desses aspectos com nomes iguais (por exemplo, falibilidade e incerteza) e complementos (por exemplo, não linearidade e não linearidade do pensamento) ou variações (por exemplo, influência motivacional, cultural, sociopolítica e histórica) são comuns a mais de uma área de conhecimento. A partir do Quadro 1, o professor poderá identificar mais facilmente qual aspecto está presente em cada área e/ou em mais de uma área. 
Revista de Educação, Ciência e Tecnologia

Quadro 1 - Identificação das áreas de conhecimento abordadas no MoCEC v.2 e de seus respectivos aspectos de $\mathrm{NdC}$

\begin{tabular}{|c|c|c|c|c|c|c|}
\hline $\begin{array}{c}\text { Áreas de } \\
\text { Conhecimento } \\
\end{array}$ & \multirow[t]{2}{*}{$\begin{array}{l}\text { Filosofia } \\
\text { da Ciência }\end{array}$} & \multirow[t]{2}{*}{$\begin{array}{l}\text { Psicologia da } \\
\text { Ciência }\end{array}$} & \multirow[t]{2}{*}{$\begin{array}{l}\text { Antropologi } \\
\text { a da Ciência }\end{array}$} & \multirow[t]{2}{*}{$\begin{array}{l}\text { Sociologia } \\
\text { da Ciência }\end{array}$} & \multirow[t]{2}{*}{$\begin{array}{r}\text { Economia } \\
\text { da Ciência }\end{array}$} & \multirow[t]{2}{*}{$\begin{array}{c}\text { História } \\
\text { da Ciência }\end{array}$} \\
\hline Aspectos de NdC & & & & & & \\
\hline Epistemologia & $\mathrm{x}$ & & & & & \\
\hline Ética & $\mathrm{x}$ & & & & & \\
\hline Lógica & $\mathrm{x}$ & & & & & \\
\hline Complexidade & & $\mathrm{x}$ & & & & \\
\hline Criatividade & & $\mathrm{x}$ & & & & \\
\hline Falibilidade & & $\mathrm{x}$ & & $\mathrm{x}$ & & \\
\hline Incerteza & & $\mathrm{x}$ & & $\mathrm{x}$ & & \\
\hline Influência & & motivacional & cultural & sociopolítica & & histórica \\
\hline Inteligência & & $\mathrm{x}$ & & & & \\
\hline Limitação & & $\mathrm{x}$ & & & & \\
\hline Não linearidade & & do pensamento & & & & $\mathrm{x}$ \\
\hline Objetividade & & $\mathrm{x}$ & & & & \\
\hline Personalidade & & $\mathrm{x}$ & & & & \\
\hline Racionalidade & & $\mathrm{x}$ & & & & \\
\hline Representação & & $\mathrm{x}$ & & & & \\
\hline Subjetividade & & $\mathrm{x}$ & & & & \\
\hline Incomensurabilidade & & & $\mathrm{x}$ & & & \\
\hline Aceitabilidade & & & & $\mathrm{x}$ & & \\
\hline Credibilidade & & & & $\mathrm{x}$ & & \\
\hline $\begin{array}{l}\text { Interação entre } \\
\text { cientistas }\end{array}$ & & & & $\mathrm{x}$ & & \\
\hline $\begin{array}{l}\text { Acesso ao } \\
\text { conhecimento }\end{array}$ & & & & & $\mathrm{x}$ & \\
\hline Aplicabilidade & & & & & $\mathrm{x}$ & \\
\hline Competitividade & & & & & $\mathrm{x}$ & \\
\hline $\begin{array}{l}\text { Fonte de } \\
\text { financiamento }\end{array}$ & & & & & $\mathrm{x}$ & \\
\hline $\begin{array}{l}\text { Investimento } \\
\text { econômico }\end{array}$ & & & & & $\mathrm{x}$ & \\
\hline Produtividade & & & & & $\mathrm{x}$ & \\
\hline Publicidade & & & & & $\mathrm{x}$ & \\
\hline Viabilidade & & & & & $\mathrm{x}$ & \\
\hline Multiplicidade & & & & & & $\mathrm{x}$ \\
\hline Progressividade & & & & & & $\mathrm{x}$ \\
\hline Provisoriedade & & & & & & $\mathrm{x}$ \\
\hline
\end{tabular}

Fonte: Santos, Maia e Justi (2020, p. 603).

Com relação ao uso do MoCEC v.2 como suporte para o planejamento de situações diferenciadas de ensino, tendo compreendido o significado de cada aspecto de $\mathrm{NdC}$, o professor pode, a partir do Quadro 1, selecionar mais facilmente quais aspectos deseja introduzir, de maneira contextualizada e explícita, por exemplo, em uma atividade de ensino. Todavia, a quantidade de aspectos e, consequentemente, de áreas que podem ser introduzidos nesses contextos, vai depender dos objetivos do professor (SANTOS; MAIA; JUSTI, 2020).

Pensando na Educação Básica, contexto no qual a sequência didática elaborada por nós pode ser desenvolvida, Santos, Maia e Justi (2020) destacam que os nomes, os significados e as respectivas áreas de conhecimento às quais os aspectos de $\mathrm{NdC}$ estão relacionados foram propostos com o objetivo de auxiliar o professor no planejamento e condução de suas aulas. Nesse sentido, elas ressaltam também que, em momentos de discussão, o professor não deve apresentar aos estudantes os nomes, os significados e as respectivas áreas às quais os aspectos estão relacionados, mas sim discutir as suas ideias centrais, caso elas não sejam apresentadas pelos próprios estudantes durante o desenvolvimento das atividades. 
Considerando este referencial, nosso objetivo pode ser expresso pela seguinte questão de pesquisa: como a segunda versão do Modelo de Ciências para o Ensino de Ciências pode favorecer a introdução de aspectos de Natureza da Ciência, de maneira contextualizada e explícita, em contextos de ensino?

\section{Aspectos metodológicos}

Esta seção tem por finalidade apresentar os aspectos metodológicos que nortearam a elaboração da sequência e das orientações destinadas ao professor. A transposição do referencial adotado neste artigo, bem como suas formas de uso e relações com a prática docente estão detalhadas ao longo do texto. A descrição dos aspectos metodológicos se fez necessária devido à escassez de literatura na área que demonstre os processos de construção de atividades que promovam situações diferenciadas de ensino e que insiram aspectos de $\mathrm{NdC}$ em contextos educacionais.

Dessa forma, a sequência didática foi elaborada com o objetivo de apresentar ao professor de Ciências como construir atividades baseadas em um referencial teóricometodológico específico para introduzir aspectos de $\mathrm{NdC}$ de maneira contextualizada e explícita em contextos de ensino. A sequência é composta por três atividades que visam abranger etapas diferentes de uma intervenção em sala de aula: (i) Atividade $^{5}$ 1, etapa inicial, visa favorecer a explicitação das ideias iniciais de estudantes sobre Ciências; (ii) Atividade 2, etapa principal, objetiva introduzir aspectos de $\mathrm{NdC}$ de maneira contextualizada e explícita; e (iii) Atividade 3, etapa final, visa identificar se, e em que extensão, houve uma ampliação da visão de estudantes sobre Ciências. Além das atividades, foram elaboradas orientações para auxiliar o professor que tenha interesse em utilizar tal sequência.

A princípio, a sequência foi proposta para estudantes das três séries do Ensino Médio, visto que esses, em comparação com estudantes do Ensino Fundamental, possuem maior maturidade para discutir aspectos de NdC. Porém, devido à diversidade de aspectos que podem ser discutidos, salientamos (na seção Resultados e discussões) que professores de outros níveis de ensino como, por exemplo, Ensino Fundamental II e Ensino Superior, podem adaptar as atividades aqui descritas às necessidades dos seus respectivos contextos.

O processo de construção da sequência iniciou-se com o estudo detalhado do referencial, envolvendo, principalmente, a compreensão do significado de cada um dos aspectos de $\mathrm{NdC}$ e a identificação daqueles a serem inseridos nas atividades, ou que pudessem emergir durante a discussão de cada uma delas.

Paralelamente, definimos um contexto que fosse potencialmente motivador para os estudantes e que favorecesse discussões explícitas sobre NdC. Em seguida, elaboramos a sequência e as orientações para o professor. Um detalhamento sobre características específicas da elaboração de cada uma das atividades é apresentado nas próximas subseções.

\subsection{Atividade 1: Visão inicial sobre Ciências}

A Atividade 1 consiste em uma série de questões contextualizadas a partir de diferentes situações que abordam, implícita ou explicitamente, cientistas, suas características, o trabalho que realizam e seus resultados. Essa etapa da sequência foi elaborada com objetivo de identificar as ideias iniciais de estudantes a respeito de quem faz Ciência, como ela é feita

\footnotetext{
${ }^{5}$ Ressaltamos que optamos pelo uso do termo Atividade com a letra inicial maiúscula quando ele se refere especificamente a uma das três atividades constituintes da sequência didática.
} 
e de sua influência na sociedade. Ela também pode contribuir para que o professor, ao tomar conhecimento das ideias iniciais de seus estudantes, possa identificar, durante e/ou ao final do processo, se e em que extensão houve uma ampliação de suas visões sobre Ciências.

Para a elaboração das questões, após o estudo detalhado do referencial, identificamos diferentes situações que evidenciam um ou mais aspectos de $\mathrm{NdC}$, de acordo com os significados apresentados no MoCEC v.2. A partir daí, elaboramos questões que contemplam tanto tais situações quanto os diferentes aspectos de $\mathrm{NdC}$ e suas respectivas áreas de conhecimento.

Juntamente com as questões, elaboramos as orientações para o professor a fim de auxiliá-lo no desenvolvimento dessa etapa. Nelas, apresentamos os objetivos das questões, reflexões sobre as situações apresentadas e, principalmente, as relações explícitas com os aspectos e suas respectivas áreas que podem ser expressos nas respostas de estudantes tanto durante o desenvolvimento da atividade quanto na sua discussão.

\subsection{Atividade 2: Aspectos de Natureza da Ciência em recortes do filme O Menino que} Descobriu o Vento

A Atividade 2 se baseia em uma seleção de recortes do filme $O$ Menino que Descobriu $o$ Vento. Essa etapa da sequência foi elaborada com o objetivo de introduzir aspectos de NdC de maneira contextualizada e explícita a partir da exibição e posterior discussão dos recortes selecionados do filme. Assim, buscamos também despertar a motivação dos estudantes para participar da atividade. Além da seleção de recortes, apresentamos a síntese das cenas que os constituem, pontos para discussão e orientações para o professor referentes a cada recorte.

A obra, que tem duração de 1 h e $53 \mathrm{~m}$ e está disponível na plataforma Netflix ${ }^{6}$, retrata a vida de William Kamkwamba, um menino negro de treze anos de idade, do Malawi. Proveniente de um contexto de muita pobreza, a família de William tinha a base de seu sustento na plantação e venda de grãos. Parte da renda gerada era utilizada como investimento na educação de William. O filme mostra também a realidade econômica e política do país e, consequentemente, do vilarejo onde o menino morava, sendo estes marcados por corrupção e miséria. O lugar estava sofrendo influências de decisões políticas que interferiram diretamente no clima local, decorrente do corte de árvores e exportação de madeira. A plantação do pai de William estava sendo devastada e o país enfrentava um período de escassez, seca e fome. Neste contexto, o menino resolveu utilizar conhecimentos desenvolvidos na escola e em seus estudos independentes na biblioteca para ajudar sua família e transformar a realidade de seu vilarejo.

A escolha deste filme se justifica pelo fato de a obra apresentar situações relacionadas ao trabalho de cientistas na busca de soluções para problemas que impactam a sociedade. Essas situações são retratadas em vários momentos e possibilitam a discussão de maneira contextualizada e explícita de aspectos de $\mathrm{NdC}$ e suas respectivas áreas de conhecimento.

A escolha também sofreu influência das críticas que encontramos a respeito da obra. A maioria dos textos trazia comentários positivos ${ }^{7}$, porém um deles ${ }^{8}$ trouxe um comentário sobre o filme poder ser considerado irreal e utópico, devido ao fato de apresentar que 'qualquer' menino negro e pobre pode ser um 'gênio' e se tornar um cientista. Ao analisarmos este último comentário sob a ótica dos significados dos aspectos de $\mathrm{NdC}$ (conforme

\footnotetext{
${ }^{6}$ https://www.netflix.com/br/title/80200047. Acesso em: 15 jul. 2020.

${ }^{7}$ https://www.rottentomatoes.com/m/the_boy_who_harnessed_the_wind/reviews. Acesso em: 15 jul. 2020

${ }^{8}$ http://www.adorocinema.com/filmes/filme-259993/. Acesso em: 15 jul. 2020
} 
apresentados no MoCEC v.2), visualizamos a potencialidade de usar este filme para elaborar uma sequência didática fundamentada em tal referencial teórico-metodológico. Isto porque a conscientização sobre as diferentes maneiras de se fazer Ciência e sobre a diversidade de classe, gênero e raça de quem faz Ciência é essencial para uma ampliação da visão de estudantes sobre Ciências. Isto também justifica o fato de esta ser a atividade principal da sequência.

A partir de um estudo minucioso do referencial que norteia este trabalho e após assistirmos ao filme atentamente por três vezes, fizemos a seleção dos recortes. Para tanto, identificamos cenas que representam situações que possibilitam a inserção e discussão de diferentes aspectos e, consequentemente, de diversas áreas do conhecimento. A seleção desses recortes foi necessária, pois a exibição do filme na íntegra poderia desviar a atenção de estudantes e, por conseguinte, levar ao não cumprimento do objetivo da atividade. Ademais, tal exibição demandaria um tempo maior de aula, o que poderia inviabilizar a aplicação da sequência em muitos contextos de ensino.

Em seguida, a fim de facilitar a mediação do professor durante o desenvolvimento desta etapa, elaboramos a síntese das cenas dos recortes selecionados. Ainda com o intuito de auxiliar, propusemos pontos para discussão a partir de questionamentos que podem ser feitos para facilitar a criação de oportunidades para que seus estudantes expressem suas ideias sobre Ciências e, ainda, tomem consciência das ideias de seus colegas (que podem ser diferentes das suas). Por fim, também elaboramos orientações para o professor visando contribuir para a discussão da atividade. Cada uma aponta explicitamente como cada aspecto de $\mathrm{NdC}$ se relaciona aos recortes selecionados.

\subsection{Atividade 3: Visão sobre Ciências após a participação nas Atividades 1 e 2}

A Atividade 3 consiste na proposta de utilização da ferramenta Edpuzzle ${ }^{9}$. Essa etapa foi elaborada com o objetivo de identificar ideias de estudantes a respeito de quem faz Ciência, como ela é feita e de suas influências na sociedade após a participação nas duas etapas anteriores. Assim, essa atividade final pode contribuir para que o professor, após ter identificado as ideias iniciais de seus estudantes (durante e/ou após a Atividade 1) e as outras ideias sobre Ciências mobilizadas e/ou desenvolvidas por eles (durante o desenvolvimento da Atividade 2), possa identificar se, e em que extensão, os estudantes modificaram suas visões sobre Ciências.

A ferramenta Edpuzzle possibilita ao professor e aos estudantes editar vídeos próprios e/ou disponíveis nas plataformas associadas (por exemplo, YouTube) de maneira interativa. Assim, ambos podem escolher um vídeo e editá-lo, além de acrescentar comentários via texto e/ou áudio destacando ideias que tenham lhes chamado a atenção nas cenas constituintes de tal vídeo. Além disto, o professor pode apresentar algumas questões via quizzes ao longo das cenas para que os estudantes respondam. A escolha dessa ferramenta se justifica pelo fato de ela ser on-line e gratuita e, portanto, de fácil acesso tanto para o professor quanto para os estudantes, e de, sendo uma ferramenta on-line, poder favorecer a motivação dos estudantes para participar da atividade.

O estudo da ferramenta foi fundamental para que pudéssemos explorar suas funcionalidades e, assim, propor uma atividade que fizesse uso de parte dela. Assim, elaboramos uma atividade na qual os estudantes devem escolher vídeos, disponíveis nas plataformas associadas à ferramenta e, consecutivamente, selecionar cenas segundo alguns

\footnotetext{
${ }^{9}$ https://edpuzzle.com/. Acesso em: 15 jul. 2020
} 
critérios relacionados à Ciência, aos sujeitos envolvidos na sua construção, e à sua influência na sociedade (apresentados na subseção 4.3), além de adicionar comentários escritos ou via áudio nas cenas selecionadas justificando suas escolhas. Optamos por explorar esta última funcionalidade devido à sua maior interatividade, se comparada às outras.

A partir desse estudo e pensando no desenvolvimento desta etapa final, elaboramos tutoriais tanto para o professor quanto para os estudantes, para mitigar possíveis dificuldades associadas ao uso da ferramenta. Durante a elaboração desses, levamos em consideração que o uso da ferramenta por parte do professor é diferente do uso feito pelos estudantes. Isto é, apesar das funcionalidades serem as mesmas, os objetivos são diferentes e, portanto, o passo a passo do uso varia. Por este motivo, tivemos o cuidado de simular o acesso de um professor e de um estudante e registrar a tela do computador evidenciando cada passo dos acessos.

Por fim, com o objetivo de validar nossa sequência didática, ela foi discutida com dois pesquisadores da área de Educação em Ciências/Química após uma análise prévia feita por cada um deles individualmente.

\section{Resultados e discussões}

Devido à limitação de espaço, optamos por apresentar, a título de exemplificação, apenas partes de cada uma das atividades constituintes da sequência didática elaborada. Nesse sentido, apresentamos: (i) uma questão contextualizada com as orientações para o professor e aspectos de $\mathrm{NdC}$ e suas respectivas áreas de conhecimento que podem ser expressos na resposta, bem como na discussão da questão; (ii) um recorte do filme com a síntese das cenas, pontos para discussão, orientações para o professor e aspectos de $\mathrm{NdC}$ e suas respectivas áreas que podem ser expressos durante e/ou após a exibição e discussão do recorte; e (iii) o enunciado da última atividade, para elucidar como o MoCEC v.2, mais especificamente os significados dos aspectos de $\mathrm{NdC}$ e, consequentemente, as áreas às quais eles se relacionam, são contemplados na sequência (tanto nas atividades quanto nas orientações para o professor). Nesta seção, apresentamos trechos retirados e adaptados da sequência didática (SIQUEIRA, 2019) e as caracterizações dos aspectos de NdC oriundas de Santos, Maia e Justi (2020).

\subsection{Atividade 1: Visão inicial sobre Ciências}

Esta atividade é composta por oito questões contextualizadas que abordam diversos temas do cotidiano. Cada questão foi elaborada a partir de diferentes temas do cotidiano com o objetivo de identificar as ideias iniciais de estudantes a respeito de quem faz Ciência e/ou como ela feita e/ou de sua influência na sociedade. Portanto, a partir dessa etapa, além de o professor tomar conhecimento sobre as ideias iniciais de seus estudantes, é possível também explicitar que a Ciência pode ser discutida a partir de diversas situações do cotidiano e, por conseguinte, de diferentes áreas de conhecimento. Assim, aspectos de $\mathrm{NdC}$ podem ser discutidos de maneira contextualizada e explícita, podendo contribuir para a ampliação da visão de estudantes sobre Ciências.

Após cada questão, orientações direcionadas ao professor foram inseridas. Essas orientações, juntamente com a identificação e apresentação dos significados dos possíveis aspectos de $\mathrm{NdC}$ que podem emergir das respostas dos estudantes (tanto durante o desenvolvimento dessa etapa quanto em sua discussão), visam orientar o entendimento sobre os aspectos de $\mathrm{NdC}$ e o desenvolvimento da atividade para que essa possa atingir seu objetivo principal. 
A título de exemplificação, selecionamos a Questão 2 juntamente com as Orientações para o professor, uma vez que ambos refletem de forma satisfatória a atividade como um todo.

Questão 2: Quais características um cientista possui? Como ele é fisicamente? Como ele se comporta? Para responder essas perguntas você pode mencionar características físicas e psicológicas de um cientista.

Orientações para o professor: Esta questão busca identificar como os estudantes visualizam e idealizam a imagem de um cientista, assim como o seu comportamento. Fatores como genialidade, isto é, um padrão intelectual; individualidade; e padrões físicos e de gênero podem ser expressos nas respostas dos estudantes. Portanto, ela favorece a discussão de aspectos de $\mathrm{NdC}$ como:

a) Inteligência (Psicologia da Ciência): características intelectuais de um cientista relativas a como ele compreende, relaciona e faz escolhas nos contextos de produção e uso de um determinado conhecimento científico, de forma que seja possível pensar no cientista com inteligência 'regular', ou seja, que não tem uma inteligência fora do padrão (é um gênio);

b) Personalidade (Psicologia da Ciência): conjunto de características marcantes próprias de um indivíduo, no caso de um cientista, que o identificam e o diferenciam dos demais, sendo utilizadas, por exemplo, para explicar seu comportamento em determinada situação ao longo dos processos de produção e uso do conhecimento científico; e

c) Interação entre cientistas (Sociologia da Ciência): diferentes modos de interação, por exemplo, parcerias, contribuições, discordâncias e disputas, devem ser levados em consideração em processos de produção e uso do conhecimento científico.

Essa etapa inicial é mais abrangente do que as Atividades 2 e 3 e, por este motivo, apresenta a possibilidade de discutir, de maneira contextualizada e explícita, 22 aspectos de $\mathrm{NdC}$ presentes em seis diferentes áreas de conhecimento, dentre os 37 elencados no Quadro 1. O professor pode usar as oito questões na ordem que preferir, ou usar apenas algumas. Isso é possível porque a diversidade de aspectos de $\mathrm{NdC}$ e, consequentemente, de áreas contempladas na Atividade 1 possibilita a discussão de diferentes situações do cotidiano relacionadas a quem faz Ciência, como ela é feita e de sua influência na sociedade, permitindo assim uma adaptação da atividade de acordo com o contexto e objetivos de ensino. Entretanto, as adaptações devem considerar que os aspectos discutidos nas questões da Atividade 1 também estejam presentes na Atividade 2, a fim de que seja possível identificar se, e em que extensão, ocorreu uma ampliação da visão sobre Ciências de estudantes.

\subsection{Atividade 2: Aspectos de Natureza da Ciência em recortes do filme $O$ Menino que Descobriu o Vento}

A Atividade 2 é composta por nove recortes do filme $O$ Menino que Descobriu o Vento, que evidenciam situações que permitem a discussão de $\mathrm{NdC}$. Todos os recortes foram selecionados para que as situações retratadas nas cenas possam ser utilizadas para introduzir aspectos de $\mathrm{NdC}$ de maneira contextualizada e explícita. Dessa forma, o objetivo da exibição desses recortes é apresentar aos estudantes novas perspectivas sobre Ciências, isto é, sobre os processos de produção e aplicação do conhecimento científico, assim como as influências que a Ciência pode sofrer e/ou exercer da e na sociedade, em relação aos seus processos.

A síntese das cenas constituintes de cada recorte auxilia o professor a enfatizar partes importantes dos trechos e, assim, direcionar a discussão para o ponto central - representado pelo nome do recorte. Por esse motivo, a síntese é constituída de um panorama geral do recorte e enfatiza os principais pontos para discussão. Esses, por sua vez, apresentam de maneira objetiva questionamentos que podem nortear a discussão e contribuir para que os 
significados dos aspectos de $\mathrm{NdC}$ identificados nas cenas possam emergir durante e/ou após a exibição e discussão dos recortes, tanto a partir das respostas dos estudantes quanto da mediação do professor. Ressaltamos que o professor não precisa, necessariamente, fazer a leitura da síntese para os estudantes durante a atividade, porém ele pode utilizá-la para enfatizar partes importantes das cenas. Ademais, o professor não precisa utilizar todos os questionamentos apresentados nos pontos para discussão.

As orientações para o professor são apresentadas a fim de explicitar a relação dos aspectos de $\mathrm{NdC}$ com as sínteses das cenas. Essas buscam auxiliar o professor na compreensão de como os aspectos de $\mathrm{NdC}$, seus respectivos significados e as áreas às quais eles se relacionam estão presentes nos recortes selecionados. Além disso, tais orientações podem contribuir para que a discussão seja mais direcionada ao objetivo dessa etapa da sequência. Vale ressaltar que a relação entre os aspectos de $\mathrm{NdC}$ apresentados nos comentários e as cenas dos recortes selecionados não está esgotada, ou seja, durante e/ou após a exibição e/ou discussão dos recortes, outros aspectos, diferentes dos identificados nas cenas, podem emergir.

Com o intuito de exemplificar, apresentamos a síntese da cena do Recorte 8, pontos para discussão e orientações para o professor. Esse recorte foi selecionado por ser representativo na atividade. Além disso, o Recorte 8 (Quadro 2) está relacionado diretamente à Questão 2 da Atividade 1, apresentada anteriormente, visto que tanto a questão quanto o recorte contemplam aspectos de $\mathrm{NdC}$ em comum (por exemplo, inteligência e personalidade, ambos da área de Psicologia da Ciência e interação entre cientistas, relacionado à área de Sociologia da Ciência). Desta maneira, evidenciamos a relação entre ambas.

Quadro 2 - Recorte 8

\begin{tabular}{l} 
Recorte 8: Mudança de realidade - Trecho 01:44:00 em diante (minutos finais do filme) \\
\hline Síntese da cena: William teve uma ideia para solucionar o problema vivenciado no vilarejo em que vivia: \\
aproveitar a força do vento para a construção de um moinho e, consequentemente, para o funcionamento de \\
uma bomba para retirar água subterrânea para irrigação da plantação. Com o sucesso da execução de sua ideia, \\
a lavoura foi restabelecida e houve uma mudança significativa na vida de todos no vilarejo. \\
Pontos para discussão: Conhecendo a história de William e o contexto em que ele estava inserido, que \\
características você atribui ao menino? As características atribuídas ao menino são parecidas com as \\
características que você atribuiu para um cientista na Atividade 1 ? Você acha que William pode ser considerado \\
um cientista? Por quê? \\
Orientações para o professor: A discussão deste recorte pode proporcionar um debate a respeito das \\
características atribuídas a um menino negro e pobre como William e das características atribuídas a um \\
cientista (na Questão 2 da Atividade 1), assim como das semelhanças e diferenças entre elas. Além disso, o \\
professor pode usar como exemplo o resultado obtido por William (com a colaboração de seus familiares, \\
vizinhos e amigos) e retomar o processo para obtenção de tal resultado a fim de enfatizar as diferentes maneiras \\
de 'ser cientista' e de se fazer Ciência. Assim, o professor pode favorecer que os estudantes reconheçam tanto a \\
diversidade dos indivíduos e dos processos de produção e aplicação do conhecimento científico, quanto as \\
influências que a Ciência pode sofrer e/ou exercer da e na sociedade, em relação aos seus processos. É válido \\
ressaltar que o estereótipo de cientista como homem, branco, com aparência de maluco e que, geralmente, \\
trabalha sozinho, foi consolidado desde o século XVIII, quando a ciência se desenvolvia de forma elitizada e \\
basicamente na Europa. Hoje, esse estereótipo não contempla a diversidade presente no meio científico, apenas \\
reforça a ideia de que 'a Ciência não é para todos'.
\end{tabular}

Fonte: Autoria própria (2020). 
Nesse sentido, os seguintes aspectos de $\mathrm{NdC}$, bem como seus significados, podem ser explorados na discussão do recorte:

a) Criatividade (Psicologia da Ciência): capacidade que um cientista possui para criar, produzir e/ou inventar algo novo, bem como inovar a partir de algo que já exista, durante os processos de produção e uso de determinado conhecimento científico;

b) Inteligência (Psicologia da Ciência): características intelectuais de um cientista relativas a como ele compreende, relaciona e faz escolhas nos contextos de produção e uso de um determinado conhecimento científico, de forma que seja possível pensar no cientista com inteligência 'regular', ou seja, que não tem uma inteligência fora do padrão (é um gênio);

c) Personalidade (Psicologia da Ciência): conjunto de características marcantes próprias de um indivíduo, neste caso de um cientista, e que o identificam e o diferenciam dos demais, sendo utilizadas, por exemplo, para explicar o seu comportamento em determinada situação ao longo dos processos de produção e uso do conhecimento científico;

d) Incomensurabilidade (Antropologia da Ciência): ideia de que não existe cultura boa ou ruim, melhor ou pior; existem diferentes culturas e, portanto, o mesmo conhecimento científico pode ser construído, interpretado e valorizado de maneiras diferentes, de acordo com as diferentes culturas; e

e) Interação entre cientistas (Sociologia da Ciência): diferentes modos de interação, por exemplo, parcerias, contribuições, discordâncias e disputas, devem ser levados em consideração em processos de produção e uso do conhecimento científico.

Essa etapa é mais específica do que a Atividade 1, pois tem como objetivo usar os recortes do filme para introduzir 13 aspectos de $\mathrm{NdC}$ presentes em quatro diferentes áreas de conhecimento, dentre os 37 elencados no Quadro 1, também de maneira contextualizada e explícita. Essa atividade também pode ser adaptada de acordo com o contexto e os objetivos de ensino. O professor pode, por exemplo, escolher um outro filme de sua preferência que também apresente potencial para introduzir aspectos de $\mathrm{NdC}$ de maneira contextualizada e explícita. Porém, ele deve considerar os aspectos discutidos nas questões da Atividade 1. Isto porque todos os aspectos inseridos na Atividade 2 foram contemplados em pelo menos uma das questões da Atividade 1. Por exemplo, o Recorte 8 favoreceu a discussão dos mesmos aspectos contemplados na Questão 2 da Atividade 1 e, além disso, incluiu outros dois aspectos (criatividade e incomensurabilidade) e uma área diferentes (Antropologia da Ciência). Essa relação entre as etapas da sequência é fundamental para que, a partir do conhecimento das ideias iniciais dos estudantes, possam ser identificadas possíveis modificações em suas visões sobre Ciências.

\subsection{Atividade 3: Visão sobre Ciências após a participação nas Atividades 1 e 2}

Essa atividade é constituída por um enunciado apresentado em uma ferramenta on-line (Edpuzzle) e deve ser desenvolvida por meio dessa. Tal ferramenta foi escolhida por possibilitar o uso e a edição de vídeos, mídia muito utilizada pelos jovens, a partir da adição de comentários. Ao utilizar um conteúdo disponível na internet e possibilitar intervenções nos vídeos, a ferramenta pode contribuir para motivar o estudante para a realização da atividade. Devido ao uso da ferramenta, essa etapa da sequência pode ser desenvolvida em casa, em sala de aula e/ou em laboratório de informática. Essa escolha fica a critério do professor, pois irá depender da infraestrutura da escola em que leciona, uma vez que sua execução requer internet, computador, tablet e/ou celular e microfone. 
A Figura 1 apresenta a tela à qual os estudantes têm acesso inicialmente. Nela são apresentados o nome da atividade $\left(\right.$ Sujeito $^{10}$ ), seu objetivo (Objetivo do projeto) e a síntese do comando da atividade (Instruções). Tal comando é: Escolha um ou mais vídeos, em uma das plataformas associadas à Edpuzzle, que apresentem situações e/ou ideias que se relacionam com o que vimos e discutimos ao longo das últimas aulas. Após a escolha dos vídeos, selecione uma ou mais cenas que retratem explicitamente situações e/ou ideias que se relacionam com o que vimos e discutimos nas Atividades 1 e 2. Por último, faça a edição dos vídeos escolhidos. Para isso, você deve fazer comentários em áudio para cada uma das cenas selecionadas e destacar as situações e/ou ideias que lhe chamaram a atenção.

Propomos que esse comando seja apresentado oralmente pelo professor, para que ele o faça da maneira mais clara para seus estudantes.

Figura 1 - Tela inicial da Atividade 3

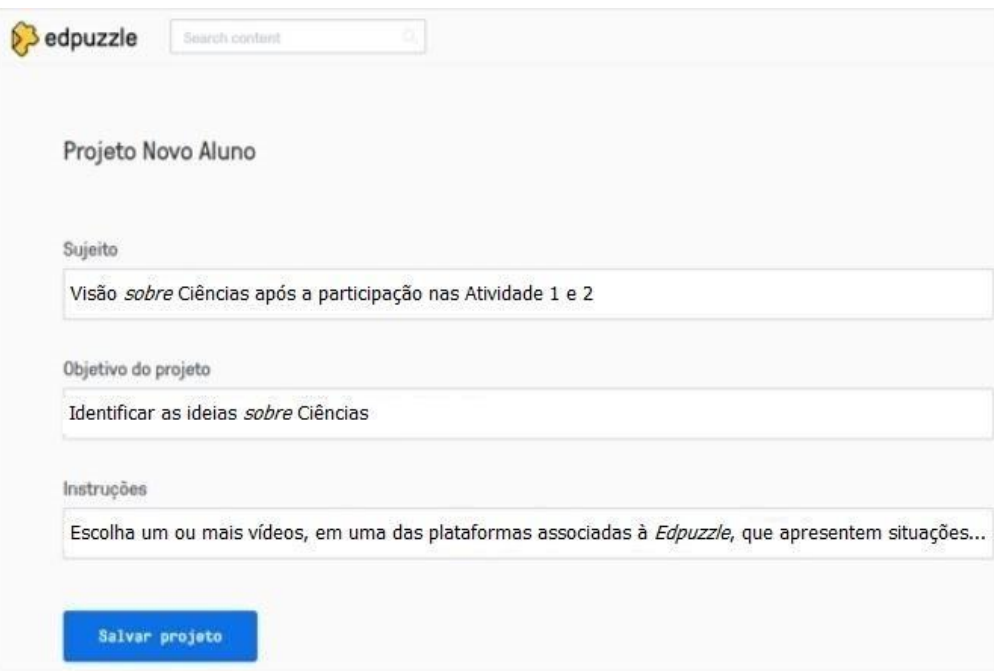

Fonte: Siqueira (2019, p. 43).

Ademais, essa etapa também é composta pelos tutoriais de uso da ferramenta por parte do professor e dos estudantes. Neles são apresentados vários registros da tela do computador ao simular o acesso de um professor e de um estudante, juntamente com explicações sobre cada um deles.

A partir (i) dos vídeos escolhidos e, consecutivamente, das cenas selecionadas pelos estudantes; (ii) dos comentários via áudio feitos por eles destacando as situações e/ou ideias que lhes chamaram a atenção em cada uma das cenas selecionadas; e (iii) do conhecimento das ideias expressas nas etapas anteriores, o professor poderá ter indícios de modificações em suas visões sobre Ciências. Por exemplo, na Atividade 1, é esperado que os estudantes deem respostas consideradas inadequadas de acordo com a perspectiva de ensino adotada neste trabalho, ou ainda, respostas sucintas. Contudo, na Atividade 2, é esperado que os estudantes deem respostas inadequadas e adequadas, ou ainda, sucintas e mais elaboradas, ou seja, aquele pode ser um momento de transição. Caso identifique a ampliação da visão sobre Ciências por parte de estudantes, o professor pode analisar em que extensão ela aconteceu a partir dos momentos de transição.

\footnotetext{
${ }^{10}$ Sujeito e Projeto Novo Aluno são nomenclaturas específicas adotadas pela própria ferramenta que, para nós, correspondem à atividade.
} 
Algumas situações e/ou ideias que podem chamar a atenção de estudantes nas cenas selecionadas e serem destacadas a partir de comentários via áudio feitos por eles podem fornecer indícios de possíveis modificações em suas ideias sobre Ciências. Alguns exemplos são apresentados para o professor:

a) Ciência não é feita apenas em laboratórios, uma vez que existem cientistas de outras áreas de conhecimento que trabalham em ambientes diferentes de laboratórios; quem faz Ciência não são apenas cientistas da área de Ciências da Natureza (por exemplo, Biologia, Física e Química), mas existem também cientistas da área de Ciências Humanas (por exemplo, Filosofia, História e Sociologia);

b) Ciência não necessariamente é feita por homens, brancos, com aparência de malucos e que, geralmente, trabalham sozinhos;

c) Ciência não é feita por um cientista isolado em seu laboratório, pois mesmo que se trate de um cientista da área de Ciências da Natureza que trabalhe em laboratório, ele não trabalha sozinho; e

d) Ciência influencia a sociedade e, portanto, pode transformar a realidade dos indivíduos que vivem em sociedade.

\subsection{Visão geral da sequência didática}

Apesar de termos elaborado a sequência didática com o objetivo de apresentar ao professor de Ciências como construir atividades de ensino baseadas em um referencial teórico-metodológico específico para introduzir aspectos de $\mathrm{NdC}$ de maneira contextualizada e explícita em contextos de ensino, pensamos também no desenvolvimento das atividades em contextos regulares de ensino. Nesse sentido, de maneira geral, seriam necessárias seis aulas de 50 minutos cada, sendo: (i) duas aulas para a Atividade 1, uma para os estudantes responderem as questões e uma para o professor discutir as respostas deles; (ii) três aulas para a Atividade 2, duas para o professor exibir os recortes e uma para discuti-los e estabelecer relações explícitas com os aspectos de $\mathrm{NdC}$ presentes neles; e (iii) uma aula para a Atividade 3, para explicação do tutorial de uso da ferramenta e para apresentação do comando da atividade - isto se o professor optar que ela seja desenvolvida em casa. Neste caso, sugerimos o prazo de uma semana para que os estudantes a desenvolvam e, depois disso, o professor pode analisar e dar um feedback para seus estudantes a partir da própria ferramenta e também de sua casa, visto que é uma ferramenta on-line.

Visando apresentar ao leitor uma visão geral de como o MoCEC v.2 pode favorecer a introdução de diversos aspectos de $\mathrm{NdC}$ de maneira contextualizada e explícita em contextos de ensino a partir de atividades que constituem uma sequência didática, identificamos, no Quadro 3, as partes das Atividades 1 e 2 (questões e recortes, respectivamente) que se relacionam a cada um dos aspectos.

O Quadro 3 evidencia que as Atividades 1 e 2 contemplam 22 aspectos de $\mathrm{NdC}$ presentes em seis diferentes áreas de conhecimento, dentre os 37 elencados no Quadro 1, sendo: (i) um da área de Filosofia da Ciência; (ii) sete da área de Psicologia da Ciência; (iii) dois da área de Antropologia da Ciência; (iv) seis (todos) da área de Sociologia da Ciência; (v) cinco da área de Economia da Ciência; (vi) um da área de História da Ciência. Portanto, as atividades constituintes da sequência didática contemplaram cerca de $60 \%$ dos aspectos apresentados no MoCEC v. 2 por Santos, Maia e Justi (2020). 
Revista de Educação, Ciência e Tecnologia

Quadro 3 - Identificação das áreas de conhecimento representadas no MoCEC v.2 e de seus respectivos aspectos de $\mathrm{NdC}$ contemplados nas Atividades 1 e 2

\begin{tabular}{|c|c|c|c|c|c|c|}
\hline $\begin{array}{c}\begin{array}{c}\text { Áreas de } \\
\text { Conhecimento }\end{array} \\
\text { Aspectos de NdC } \\
\end{array}$ & $\begin{array}{c}\begin{array}{c}\text { Filosofia } \\
\text { da } \\
\text { Ciência }\end{array} \\
\end{array}$ & $\begin{array}{l}\text { Psicologia } \\
\text { da Ciência }\end{array}$ & $\begin{array}{c}\text { Antropologia } \\
\text { da Ciência }\end{array}$ & $\begin{array}{l}\text { Sociologia } \\
\text { da Ciência }\end{array}$ & $\begin{array}{l}\text { Economia } \\
\text { da Ciência }\end{array}$ & $\begin{array}{l}\text { História } \\
\text { da } \\
\text { Ciência }\end{array}$ \\
\hline Epistemologia & Questão 5 & & & & & \\
\hline \multicolumn{7}{|l|}{ Ética } \\
\hline \multicolumn{7}{|l|}{ Lógica } \\
\hline \multicolumn{7}{|l|}{ Complexidade } \\
\hline Criatividade & & $\begin{array}{c}\text { Questão } 1 \\
\text { Recortes } 1,4 \mathrm{e} \\
8 \\
\end{array}$ & & & & \\
\hline Falibilidade & & & & Questão 6 & & \\
\hline Incerteza & & & & Questão 6 & & \\
\hline Influência & & $\begin{array}{l}\text { Questões } 5 \text { e } 8 \\
\text { Recorte } 3\end{array}$ & $\begin{array}{c}\text { Questão 5 } \\
\text { Recortes } 3 \text { e } \\
9\end{array}$ & $\begin{array}{c}\text { Questão } 5 \\
\text { Recortes } 3 \text { e } 9\end{array}$ & & Questão 5 \\
\hline Inteligência & & $\begin{array}{l}\text { Questão } 2 \\
\text { Recorte } 8 \\
\end{array}$ & & & & \\
\hline Limitação & & $\begin{array}{l}\text { Questão } 6 \\
\text { Recorte } 5\end{array}$ & & & & \\
\hline \multicolumn{7}{|l|}{ Não linearidade } \\
\hline \multicolumn{7}{|l|}{ Objetividade } \\
\hline Personalidade & & $\begin{array}{c}\text { Questão } 2 \\
\text { Recortes } 1 \text { e } 8\end{array}$ & & & & \\
\hline \multicolumn{7}{|l|}{ Racionalidade } \\
\hline Representação & & $\begin{array}{c}\text { Questão } 6 \\
\text { Recortes } 5 \text { e } 6\end{array}$ & & & & \\
\hline Subjetividade & & Questão 5 & & & & \\
\hline Incomensurabilidade & & & $\begin{array}{l}\text { Questão } 7 \\
\text { Recorte } 8\end{array}$ & & & \\
\hline Aceitabilidade & & & & Questões 3 e 7 & & \\
\hline Credibilidade & & & & $\begin{array}{c}\text { Questões } 3 \text { e } 7 \\
\text { Recorte } 5\end{array}$ & & \\
\hline $\begin{array}{l}\text { Interação entre } \\
\text { cientistas }\end{array}$ & & & & $\begin{array}{c}\text { Questões } 2 \text { e } 4 \\
\text { Recortes } 4,7 \text { e } \\
8 \\
\end{array}$ & & \\
\hline $\begin{array}{l}\text { Acesso ao } \\
\text { conhecimento }\end{array}$ & & & & & $\begin{array}{c}\text { Questões } 4 \text { e } \\
7 \\
\text { Recortes } 2 \mathrm{e} \\
9\end{array}$ & \\
\hline Aplicabilidade & & & & & $\begin{array}{c}\text { Questão } 4 \\
\text { Recortes } 1 \text { e } \\
9 \\
\end{array}$ & \\
\hline \multicolumn{7}{|l|}{ Competitividade } \\
\hline $\begin{array}{l}\text { Fonte de } \\
\text { financiamento }\end{array}$ & & & & & Questão 6 & \\
\hline $\begin{array}{l}\text { Investimento } \\
\text { econômico }\end{array}$ & & & & & Questão 6 & \\
\hline Produtividade & & & & & Questão 4 & \\
\hline \multicolumn{7}{|l|}{ Publicidade } \\
\hline \multicolumn{7}{|l|}{ Viabilidade } \\
\hline \multicolumn{7}{|l|}{ Multiplicidade } \\
\hline \multicolumn{7}{|l|}{ Progressividade } \\
\hline Provisoriedade & & & & & & \\
\hline
\end{tabular}

Fonte: Os autores.

\section{Considerações finais}

Nas seções anteriores, elucidamos como o MoCEC v.2, como referencial teóricometodológico, pode favorecer a introdução de aspectos de $\mathrm{NdC}$ de maneira contextualizada e explícita em contextos de ensino. Isto foi possível porque essa versão do modelo apresenta e caracteriza esses aspectos detalhada e didaticamente. Assim, a partir dos significados de cada 
um dos aspectos de $\mathrm{NdC}$ foi possível elaborar questões e orientações para o professor, selecionar recortes do filme escolhido e identificar alguns aspectos presentes nas cenas. Além disso, apresentamos, a título de exemplificação, partes de cada uma das atividades retiradas e adaptadas da sequência didática apresentada em Siqueira (2019), elaborada a partir de tal referencial.

Nesse sentido, uma das contribuições de nosso trabalho para o ensino é a própria sequência que pode ser utilizada pelo professor que tenha interesse em introduzir aspectos de NdC de maneira contextualizada e explícita no ensino de Ciências, e favorecer a ampliação da visão sobre Ciências de seus estudantes. Pensando no professor que tenha interesse em utilizar a sequência, elaboramos orientações visando auxiliá-lo no desenvolvimento das atividades que a constituem em salas de aula, bem como uma proposta de planejamento para o desenvolvimento de tal sequência. Além disso, apresentamos o uso de filmes como estratégia de ensino, e o uso de ferramentas on-line e gratuitas que, no atual contexto de pandemia causada pelo coronavírus SARS-CoV-2, talvez nunca tenham sido tão importantes e necessárias.

Todavia, ressaltamos que como o nosso objetivo primeiro era elucidar como um referencial teórico-metodológico pode ser utilizado para estruturar atividades de ensino na perspectiva considerada neste trabalho. Tal sequência ainda não foi desenvolvida em salas de aula, mas pretendemos que isto aconteça em breve, para que possamos compartilhar os resultados obtidos.

Quando pensamos no desenvolvimento das Atividades 1, 2 e 3, visamos contribuir para ampliação da visão sobre Ciências de estudantes que as vivenciem em contextos regulares de ensino e aprendizagem. Por outro lado, ao elaborarmos esta sequência, foi possível perceber a ampliação de nossa própria visão sobre Ciências. A primeira autora deste artigo, por exemplo, estava no final do curso de Química Licenciatura e, ainda assim, não tinha lido nem discutido sobre a temática NdC. Portanto, antes da efetiva elaboração da sequência, ela precisou tomar conhecimento da temática e, após selecionar o referencial no qual as atividades foram baseadas, precisou estudá-lo detalhadamente. Isso foi feito para que ela compreendesse o significado de cada um dos possíveis aspectos de $\mathrm{NdC}$ a serem inseridos nas atividades, o que contribuiu para ampliação de sua própria visão sobre Ciências.

Por fim, este trabalho também tem implicações para a pesquisa na medida em que elucida como um referencial teórico-metodológico pode ser utilizado para estruturar atividades de ensino. Isto amplia o horizonte de pesquisas tanto com relação aos resultados da introdução de aspectos de $\mathrm{NdC}$ em contextos de ensino na Educação Básica, quanto aos conhecimentos necessários para que professores atuem na perspectiva de ensino aqui apresentada. Em todos os casos, os resultados de pesquisas futuras podem fomentar o diálogo entre pesquisadores e professores envolvendo a temática $\mathrm{NdC}$ na área de Educação em Ciências.

\section{Financiamentos e agradecimentos}

As autoras agradecem: à CAPES, pelos auxílios financeiros que lhes possibilitaram dedicar tempo para desenvolver esta pesquisa; aos dois pesquisadores da área de Educação em Ciências/Química, por terem contribuído na validação da sequência; e à Rosária Justi, pela leitura crítica do artigo e apontamentos que contribuíram para a produção da versão submetida. 
ALLCHIN, D. Beyond the Consensus View: Whole Science. Canadian Journal of Science, Mathematics and Technology Education, v. 17, n. 1, p. 18-26, 2017. DOI 10.1080/14926156.2016.1271921. Disponível em: http://dx.doi.org/10.1080/14926156.2016.1271921. Acesso em: 24 jun. 2020.

ALLCHIN, D. Evaluating Knowledge of The Nature of (Whole) Science. Science Education, v. 95, n. 3, p. 518-542, mar. 2011. DOI 10.1002/sce.20432. Disponível em: http://dx.doi.org/10.1002/sce.20432. Acesso em: 25 jun., 2020.

ALLCHIN, D. How Can History and Philosophy of Science Contribute to Understanding the Nature of Science for Scientific Literacy? Mapping Research Needs. In: Conference on How Can the HPS Contribute to Contemporary. U.S, Boston, 2012.

ALLCHIN, D. Teaching the Nature of Science: perspectives \& resources. Minnesota: SHiPS Educational Press, 2013. 310p.

ERDURAN, S.; DAGHER, Z. R. Reconceptualizing nature of science for science education. In: ERDURAN, S.; DAGHER, Z. R. Reconceptualizing the Nature of Science for Science Education: contemporary trends and issues in science education. Dordrecht: Springer, 2014. p. 1-18. E-book. DOI 10.1007/978-94-017-9057-4_1.

GILBERT, J. K. Models and Modelling: Routes to more Authentic Science Education. International Journal of Science and Mathematics Education, v. 2, n. 2, p. 115-130, 2004. DOI 10.1007/s10763-004-3186-4. Disponível em: http://dx.doi.org/10.1007/s10763-0043186-4. Acesso em 24 jun., 2020.

IRZIK, G.; NOLA, R. A Family Resemblance Approach to The Nature of Science for Science Education. Science \& Education, v. 20, n. 7-8, p. 591-607, 25 ago. 2011. DOI 10.1007/s11191-010-9293-4. Disponível em: http://dx.doi.org/10.1007/s11191-010-9293-4. Acesso em: 25 jun., 2020.

IRZIK, G.; NOLA, R. New Directions for Nature of Science Research. International Handbook of Research in History, Philosophy and Science Teaching, p. 999-1021, 30 dez. 2014. DOI 10.1007/978-94-007-7654-8_30. Disponível em: http://dx.doi.org/10.1007/978-94007-7654-8_30. Acesso em: 25 jun., 2020.

JUSTI, R.; ERDURAN, S. Characterizing Nature of Science: A Supporting Model for Teachers. In: Conference of the International History, Philosophy, and Science. Rio de Janeiro: Teaching Group, 2015.

LEDERMAN, N. G.; ABD-EL-KHALICK, F.; BELL, R. L.; SCHWARTZ, R. S. Views of Nature of Science Questionnaire: Toward Valid and Meaningful Assessment of Learners' Conceptions of Nature Of Science. Journal of Research in Science Teaching, v. 39, n. 6, p. 497-521, 2002. DOI 10.1002/tea.10034. Disponível em: http://dx.doi.org/10.1002/tea.10034. Acesso em: 24 maio, 2020.

MATTHEWS, M. R. Changing the Focus: From Nature of Science (NOS) to features of science (FOS). Advances in Nature of Science Research, p. 3-26, 14 set. 2012. DOI 10.1007/978-94-007-2457-0_1. Disponível em: http://dx.doi.org/10.1007/978-94-007-24570_1. Acesso em: 24 maio, 2020. 
Revista de Educação, Ciência e Tecnologia

MCCOMAS, W. F. Seeking Historical Examples to Illustrate Key Aspects of the Nature of Science. Science \& Education, v. 17, n. 2-3, p. 249-263, 2008. DOI 10.1007/s11191-0079081-y. Disponivel em: http://dx.doi.org/10.1007/s11191-007-9081-y. Acesso em 25 jun., 2020.

MILLAR, R.; OSBORNE, J. Beyond 2000: Science Education for the Future. London: King's College and London School of Education, 1998. 36p.

OSBORNE, J.; COLLINS, S.; RATCLIFFE, M.; MILLAR, R.; DUSCHL, R. What "ideasabout-science" should be taught in school science? A Delphi Study of the Expert Community. Journal of Research in Science Teaching, v. 40, n. 7, p. 692-720, 2003. DOI 10.1002/tea.10105. Disponível em: http://dx.doi.org/10.1002/tea.10105. Acesso em 24 jun., 2020.

SANTOS, M.; MAIA, P.; JUSTI, R. Um modelo de ciências para fundamentar a introdução de aspectos de natureza da ciência em contextos de ensino e para analisar tais contextos.

Revista Brasileira de Pesquisa em Educação em Ciências, Belo Horizonte, v. 20, p. 581616, jul. 2020. DOI 10.28976/1984-2686rbpec2020u581616. Disponível em:

http://dx.doi.org/10.28976/1984-2686rbpec2020u581616. Acesso em: 27 jul. 2020.

SASSERON, L. H.; CARVALHO, A. M. P. Alfabetização científica: uma revisão bibliográfica. Investigações em Ensino de Ciências, v. 16, n. 1, p. 59-77, 2011. Disponível em: https://www.if.ufrgs.br/cref/ojs/index.php/ienci/article/view/246. Acesso em: 12 jun. 2020 .

SIQUEIRA, E. C. P. 2019. A Inserção e Discussão de Aspectos de Natureza da Ciência em Sala de Aula a partir do Filme O Menino que Descobriu o Vento. 2019. 84f. Trabalho de Conclusão de Curso (Graduação em Química Licenciatura) - Departamento de Química, Instituto de Ciências Exatas, Universidade Federal de Minas Gerais.

Recebido em agosto de 2020.

Aprovado em novembro de 2020. 